\title{
SETTING TIME, FLOWABILITY, AND SOLUBILITY OF EPOXY RESIN-BASED SEALER MIXED WITH CHITOSAN NANOPARTICLES
}

\section{DIATRI NARI RATIHa* ${ }^{*}$, RARAS AJENG ENGGARDIPTAa , ADI NUGROHO HENDRO KUSUMO ${ }^{b}$, WIGNYO HADRIYANTOa}

aDepartment of Conservative Dentistry, Faculty of Dentistry, Universitas Gadjah Mada, Yogyakarta, Indonesia, bFormer Student. Specialist Study Program of Conservative Dentistry, Faculty of Dentistry, Universitas Gadjah Mada, Yogyakarta, Indonesia

*Email: diatri@ugm.ac.id

Received: 17 Nov 2020, Revised and Accepted: 15 Dec 2021

\section{ABSTRACT}

Objective: The purpose of this study was to investigate the effect of the incorporation of chitosan nanoparticles into epoxy resin-based sealer on its setting time, flowability and solubility.

Methods: This study was divided into three evaluations: setting time, flowability, and solubility of sealers. Each study used 20 samples, which were divided into two groups. Group 1, epoxy resin-based sealers, and group 2, epoxy resin-based sealers mixed with chitosan nanoparticles. The Gilmore needle was used to observe the setting time, a simple press method based on ISO 6876 was employed to evaluate the flowability of the sealer, and the solubility test, which was according to ISO 6876 standard, was used to determine the solubility of sealers. The surface structure of the sealers before and after the solubility test was observed under Scanning Electron Microscopy (SEM). The data obtained from each study were analyzed by an unpaired t-test with a degree of significance of $95 \%$.

Results: The results showed that the setting time of epoxy resin and epoxy resin incorporated with chitosan were $567 \pm 30.20$ and $572.5 \pm 27.91 \mathrm{~min}$, flowability was $25.06 \pm 0.89$ and $23.18 \pm 1.06 \mathrm{~mm}$, and solubility was $0.0051 \% \pm 0.0016$ and $0.0045 \% \pm 0.0018$, respectively. No significant difference occurred between epoxy resin-based sealer and epoxy resin-based sealer mixed with chitosan nanoparticles in setting time, flowability, and solubility of sealers $\left({ }^{*} \mathrm{P}>0.05\right)$.

Conclusion: The incorporation of chitosan nanoparticles produced a similar effect in setting time, flowability, and solubility as the epoxy resinbased sealer. Thus, epoxy resin-based sealer mixed with chitosan nanoparticles had acceptable properties in setting time, flowability, and solubility based on ISO 6876 standards.

Keywords: Setting time, Flowability, Solubility, Epoxy resin-based sealer, Chitosan nanoparticle

(C) 2021 The Authors. Published by Innovare Academic Sciences Pvt Ltd. This is an open access article under the CC BY license (https://creativecommons.org/licenses/by/4.0/) DOI: https://dx.doi.org/10.22159/ijap.2021v13i2.40270. Journal homepage: https://innovareacademics.in/journals/index.php/ijap

\section{INTRODUCTION}

Root canal sealers are crucial in the obturation of the root canal and are used in association with gutta-percha. The purpose of using a root canal sealer is to assurance the closure of the root canal system of the teeth, thereby eliminating residual microorganisms and avoiding ingress of any bacteria from the oral environment to periapical tissues $[1,2]$. Sealers also assist the positioning of the master gutta-percha cone and perform as a linking agent between the gutta-percha and the canal wall, filling remaining spaces. Therefore, sealers must be capable of providing a fluid-tight seal [3]. Although root canal sealers used only as additional materials in the root canal system's obturation have been revealed to affect the result of root canal treatment [4]. The ideal root canal sealer must have biocompatibility, antibacterial, good apical sealing ability, adequate flowability, insoluble in tissue fluid, and no coloring to teeth $[5,6]$.

The epoxy resin-based sealer has recently been popular as root canal obturation material because it has several beneficial properties such as good apical closure, adequate flowability, low setting time, and solubility [4, 7]. However, according to previous studies, the epoxy resin-based sealer has low antibacterial properties; hence the possibility of adding a high antibacterial material to the epoxy resin-based sealer might enhance its antibacterial property [8-10]. Besides, the addition of nano-sized fillers into the resin-based sealer could increase the bond strength between the sealer and the root canal dentin, leading to enhance apical sealing ability [11].

Chitosan has been widely used in dentistry due to its beneficial properties, namely bio-degradation, biocompatibility, bio-adhesion, and non-toxic to human cells. Chitosan is a non-toxic natural polysaccharide generated from the deacetylation of chitin, which is attained from the shells of crustaceans and shrimp [12]. Previous studies have elucidated that chitosan has antibacterial properties against $E$ faecalis and $C$ albicans $[13,14]$.

Incorporating chitosan nanoparticles into an epoxy resin-based sealer is interesting to be studied to increase its antibacterial property, especially against $E$ faecalis, and enhancing its adhesion to the root canal dentin wall. However, the addition of chitosan nanoparticles should not affect the physical properties of root canal sealers, and it must follow the requirements in the International Standards Organization (ISO) 6876 standard for root canal sealing materials $[6,15]$. Nowadays, no study has evaluated the incorporation of chitosan nanoparticles into epoxy resin-based sealers on its physical properties, such as setting time, flowability, and solubility. These physical properties of the sealer are important parameters and needed to be investigated because setting time indicates adequate working time and sufficient consistency to fulfill the root canal sealer property [16]. The flowability of the sealer determines the ability of the sealer to penetrate the root canal, especially to the accessory canal; hence it can fill the voids between the main gutta-percha and gutta-percha accessories [17]. The solubility of sealers needs to be evaluated because it could release materials that are able to irritate periapical tissues. The solubility could also create a gap between the root canal wall and obturation material, resulting in apical leakage [18]. Therefore, the aim of this study was to evaluate the effect of the incorporation of chitosan nanoparticles into epoxy resin-based sealer on its setting time, flowability and solubility.

\section{MATERIALS AND METHODS}

The protocol of this study was approved by the Institutional Ethics Committee, no. 00109/KKEP/FKG-UGM/EC/2019. Chitosan was synthesis from shrimp shells (degree of deacetylation>75\%) using 
the ionic glass method and Polyanion Tripolyphosphate (TPP) as a crosslinker [19]. This study was divided into three evaluations, the first study evaluated the setting time of sealer, the second study evaluated flowability of sealer, and the third study evaluated solubility of sealers. Each study used 20 samples randomly assigned into two groups of 10 each. Group 1 used epoxy resin-based sealer (AH 26, De Trey, Dentsply, Konstanz, Germany), and group 2 used epoxy resin-based sealer (AH 26, De Trey, Dentsply) mixed with chitosan nanoparticle. The epoxy resin-based sealer (Group 1) was mixed by the same operator on a glass plate according to the manufacturer's instruction, namely two units of powder $(100 \mathrm{mg})$ with one resin unit $(50 \mathrm{mg}$ ) using a spatula until the mixture evenly mixed and could be pulled up to $1.5-2.5 \mathrm{~cm}$. Group 2 used an epoxy resin-based sealer mixed with chitosan nanoparticles. Chitosan nanoparticles were added to epoxy resin-based sealer powder by comparison between chitosan nanoparticles $(15 \mathrm{mg})$ with epoxy resin-based sealer powder (100 $\mathrm{mg})$ [15]. Both ingredients were mixed thoroughly using a spatula. The mixture was mixed with oneunit resin $(57.7 \mathrm{mg})$ using a spatula until it was thoroughly mixed and could be pulled up to $1.5-2.5 \mathrm{~cm}$.

\section{Setting time evaluation}

The setting time of the sealers was determined according to the ISO 6876 specification [15]. This study used 20 samples were randomly assigned into two groups of 10 each. Group 1: epoxy resin-based sealer (AH 26, De Trey, Dentsply), and group 2: epoxy resin-based sealer (AH 26, De Trey, Dentsply) mixed with chitosan nanoparticle. All sealers were mixed and manipulated in the same manner above. The sealer mixture was inserted into the metallic molds $(10 \mathrm{~mm}$ in diameter and $2 \mathrm{~mm}$ in height), then transferred to a chamber with $95 \%$ relative humidity and temperature of $37^{\circ} \mathrm{C}$. After the initial setting time, the Gilmore needle with a weight of $110 \mathrm{~g}$ and a tip diameter of $2 \mathrm{~mm}$ was lowered vertically onto the horizontal surface of each sample. The setting times were determined as the time elapsed from the commencing of mixing to the time at which no indentation was noticed on the surface of the specimens. Three measurements were done for each sealer.

\section{Flowability evaluation}

This evaluation also used 20 samples, which were randomly divided into two groups of 10 each. Group 1: epoxy resin-based sealer $(\mathrm{AH}$ 26, De Trey, Dentsply), and group 2: epoxy resin-based sealer (AH 26 , De Trey, Dentsply) mixed with chitosan nanoparticle. All sealers were mixed and manipulated in the same manner above. The mixed sealers were then placed in the middle of the glass plate. After $180 \mathrm{~s}$ following the start of mixing, another glass plate with a mass of $20 \pm 2$ $\mathrm{g}$ and a load of $100 \mathrm{~N}$ was placed in the middle on the top of the plate; therefore, the total weight was $120 \mathrm{~g}$. Ten minutes after beginning the mixing, the load was removed, and the average of the maximum and minimum diameters of the compressed disc was measured by the digital calipers (Mintuyo MTI Corporation, Tokyo, Japan). If the difference between both diameters was not more than $1.0 \mathrm{~mm}$, the results were recorded.

\section{Solubility evaluation}

This study used 20 samples were randomly assigned into two groups of 10 each. Group 1: epoxy resin-based sealer (AH 26, De Trey, Dentsply), and group 2: epoxy resin-based sealer ((AH 26, De Trey, Dentsply) mixed with chitosan nanoparticles. All sealers were mixed and manipulated in the same manner above. The solubility of sealer was carried out in accordance with ISO 6876 standards [15]. Teflon ring molds with an inner diameter of $7.5 \mathrm{~mm}$ and a thickness of $1.5 \mathrm{~mm}$ were used for sample preparation. The molds were placed on a glass plate and covered with a cellophane sheet. A nylon thread was located inside the sealer material, and another glass plate, which was also covered with cellophane film, was positioned on the mold and pressed manually; hence the plates touched the entire mold in a uniform manner. All samples were stored in an incubator $\left(37^{\circ} \mathrm{C}\right.$, with $95 \%$ relative humidity) and left to stand for a period corresponding to three times of setting time.

After setting, the specimens were removed from the molds, and any loose material was removed from the surface. Each sample was weighed three times using an analytical balance with $0.0001 \mathrm{~g}$ (Mettler Toledo, Jiangsu, China). The samples were suspended by nylon thread and placed inside the glassware containing deionized distilled water. Special attention was taken to keep the specimens hung in the water, not touching the walls of glassware. The containers were stored for $7 \mathrm{~d}$ in an incubator $\left(\left(37^{\circ} \mathrm{C}\right.\right.$, with $95 \%$ relative humidity). After this period, the samples were then removed from the container and washed with distilled water, dried with absorbent paper, placed in the oven for $24 \mathrm{~h}$ and then weighed again. The experiment was repeated three times for each sealer. Solubility was determined by calculating the weight loss (initial mass-final mass), expressed as the percentage of the original mass. This value indicated the solubility of the sealer.

All samples before and after the solubility test were observed under SEM. All samples were secured on metal stubs, desiccated, and sputter-coated with gold, and the morphologies of the external surface of the samples were qualitatively analyzed using SEM (JEOL JSM-5510, Tokyo, Japan) at 1000x magnification.

\section{Statistical analysis}

Data of setting time, flowability and solubility were presented as mean and standard deviation (SD). The data obtained from each study were analyzed by an unpaired t-test with a degree of significance of $95 \%$.

\section{RESULTS}

The results of this setting time study (table 1 ) for both sealers were in the range of ISO 6876 standard, which was more than $30 \mathrm{~min}$ and less than $72 \mathrm{~h}$. This study also showed a longer setting time of epoxy resin-based sealer mixed with chitosan nanoparticles, although both sealers were not significantly different $(* \mathrm{P}>0.05)$ (table 2 ).

Even though an insignificant difference occurred between both sealers $(* P>0.05)$ (table 2$)$, epoxy resin-based sealer mixed with chitosan nanoparticles produced greater flowability than epoxy resin-based sealer (table 1). According to ISO 6876 standard, both sealers fulfilled the criteria as a sealer since the diameter was greater than $20 \mathrm{~mm}$.

Regarding solubility, it can be seen that both sealers met the criteria of ISO 6876 standard, which should not exceed $3 \%$ by mass when the solubility of the set material is tested. Both sealers revealed no significant differences occurred in solubility $\left({ }^{*} \mathrm{P}>0.05\right)$ (table 2$)$.

Representative SEM micrograph of samples before and after water storage for $7 \mathrm{~d}$ is presented in fig. 1 and 2. It was noted that all surfaces of the sealers had micromorphological changes after the solubility test. The epoxy resin-based sealer had an external surface that appeared to be mostly homogenous rough surface and uniformly scattered globular-like particles (fig. $1 \mathrm{~A}$ ). The loss of matrix was apparent, and the filler particles were more noticeable (fig. 1 B). The chitosan nanoparticles were distinguishable on the surface of the epoxy resinbased sealer mixed with chitosan nanoparticles before the solubility test (fig. 2 A). After the solubility test, the surface appeared to be similar to before; although some matrix dissolved, chitosan nanoparticles remained obvious embedded in the sealer (fig. 2 B).

Table 1: Mean and standard deviation of incorporation of chitosan nanoparticles into epoxy resin-based sealer on setting time, flowability, and solubility

\begin{tabular}{lccc}
\hline Sealers & Setting time (min) & Flowability (mm) & Solubility (\%) \\
\hline Epoxy resin & $567 \pm 30.20$ & $25.06 \pm 0.89$ & $0.0051 \pm 0.0016$ \\
Epoxy resin+chitosan nanoparticles & $572.5 \pm 27.91$ & $23.18 \pm 1.06$ & $0.0045 \pm 0.0018$ \\
\hline
\end{tabular}

$\mathrm{n}=10$ in each study and data are given in mean \pm SD 
Table 2: Analysis using t-test of incorporation of chitosan nanoparticles to epoxy resin-based sealer on setting time, flowability, and solubility

\begin{tabular}{lll}
\hline Treatment & T & P \\
\hline Setting time & 0.007 & 0.937 \\
Flowability & 0.918 & 0.351 \\
Solubility & 0.774 & 0.390 \\
\hline
\end{tabular}

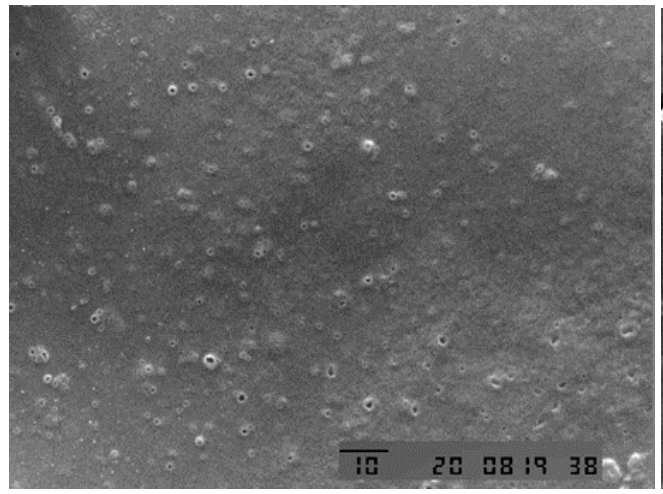

(A)

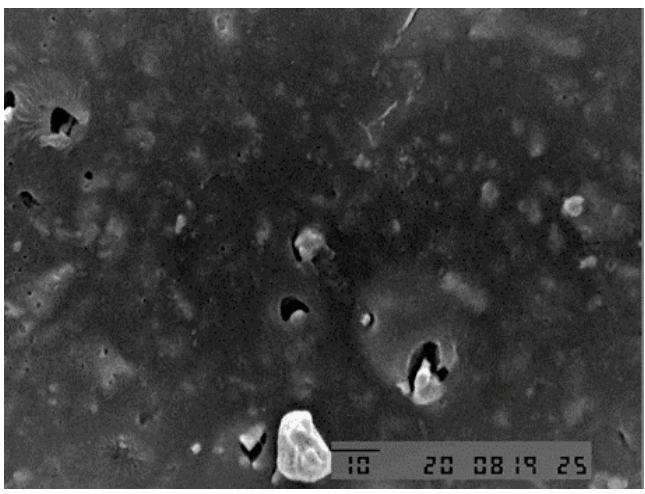

(B)

Fig. 1: Epoxy resin-based sealer before solubility test demonstrated the external surface was observed homogeneously rough (A); Epoxy resin-based sealer after solubility test exhibited the external surface was observed the loss of some matrix and the detachment of filler particles were more noticeable (B). Original magnification X1000

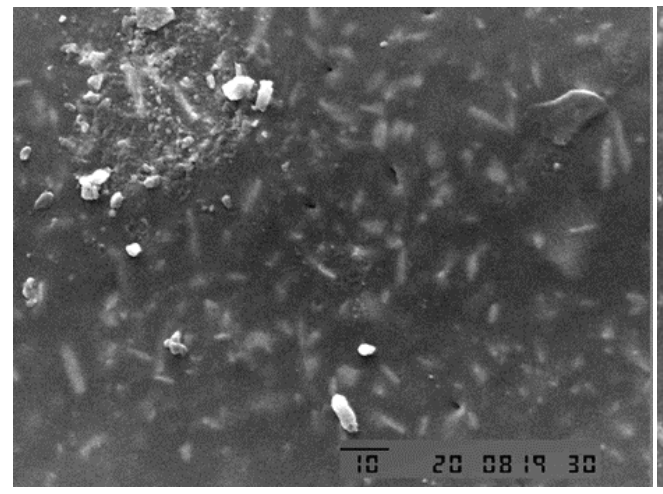

(A)

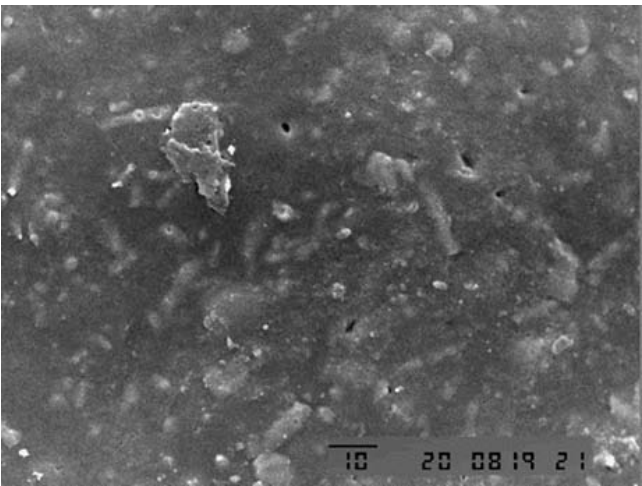

(B)

Fig. 2: Epoxy resin-based sealer mixed with chitosan nanoparticles before solubility test revealed the external surface was observed homogeneously rough and chitosan nanoparticles were distinguishable (A); Epoxy resin-based sealer mixed with chitosan nanoparticles before solubility test revealed the external surface was observed less matrix loss and chitosan nanoparticles remained obvious embedded in the sealer (B). Original magnification X1000

\section{DISCUSSION}

It is essential to generate standardized procedures to evaluate the physicochemical properties of a new and gold standard of materials, such as root canal sealers. The standardizations were established after the publication of ISO 6876 [20]. Although there is no specific standard for the setting time of root canal sealers, the dentist needs adequate working time for material placement in the root canal. Setting time is principally a control assessment on the stable behavior of a product, and this parameter relies on several factors, for example, the constituent of components, particle size, the ambient temperature, and relative humidity [21]. In the present study, the setting time of both sealers was in accordance with ISO 6876 . Both sealers produced almost a similar setting time and were appropriate in the range of the setting time stated in the manufacturer's instruction, which is 24 to $36 \mathrm{~h}$. In this study, humidity and temperature were controlled for both sealers.

The setting of a sealer occurs due to the reaction between the two components of the material (powder with liquid). The long setting time of epoxy resin-based sealer may be due to the that sealer consists of powder and liquid, namely the bisphenol-epoxy resin and hexamethylenetetramine, which needs a slow polymerization reaction of epoxy resin amines with high molecular weight. Therefore, the conversion of polymers from monomers occurs slowly [22]. The incorporation of chitosan nanoparticles into epoxy resin-based sealer produced a longer setting time compared to epoxy resin-based sealer because the addition of particles that do not contribute to the reaction during setting or polymerization may enhance the setting time [23].

The long setting time might generate advantages of both sealers since it leads to no cracking or rapid separation from dentinal walls resulting in good adhesion to the root canal wall. However, this setting time of the sealer cannot be very long because the contact of the sealer with the periapical tissues may cause irritation and influence the biocompatibility. Additionally, a long time to harden may increase solubility, creating gaps that could be occupied by microorganisms resulting in reinfection [24].

Among the root canal sealers available in the market, epoxy resinbased sealers have been widely used for obturation material due to 
their resorption resistance and dimensional stability [16]. Besides, the epoxy resin-based sealer has antibacterial property, good flow, low toxicity, and well tolerated by periapical tissue, biocompatibility, low solubility, and shrinkage, sealing ability, adequate working time and penetration into dentinal tubules, as well as good handling characteristic [25].

The crucial consideration for the use of sealers in the root canal is flowability. The greater the penetrating capability of sealer into dentinal tubules, the greater the ability to trap microorganisms and prevent their growth. The flow and penetration ability of sealers between gutta-percha cones and into the accessory canals are also essential [17]. According to ISO 6876 [15], the sealers should have a diameter of not less than $20 \mathrm{~mm}$ at the flowability test. In the present study, the flow of epoxy resin-based sealer and epoxy resinbased sealer mixed with chitosan nanoparticles were measured at $25.06 \pm 0.89 \mathrm{~mm}$ and $23.18 \pm 1.06 \mathrm{~mm}$, respectively. Therefore, both sealers fulfilled the ISO 6876 specifications. The flowability of sealers affected by several factors such as film thickness, particle size, temperature, rate of insertion, the internal diameter of the canal, powder/liquid, and shear rate. In this study, the incorporation of chitosan nanoparticle, which has nanoparticle size, could influence the flowability of sealers $[1,21]$.

According to previous investigators, an endodontic sealer should have a moderate flow rate since undue flow enhances the risk of extravasation and deficient flow decreases the sealer penetration in accessory canals. Additionally, flowability is an essential factor in achieving hermetic seal of root canal obturation because low flow within the working time may induce endodontic sealer to reach seal the apical foramen and lateral dentinal wall irregularities [9]. Conversely, high flowability might result in extrusion of sealer through the apical foramen to the periapical tissues, thereby compromise healing [26, 27].

As previously stated, the flowability is affected by the size of sealer particles. This statement is consistent with this present study that revealed the incorporation of chitosan even though in nano-size particles produced a lower flowability compared to the epoxy sealer-based sealer. Preferably, an endodontic sealer must have reasonable flowability since excessive flow increases the risk of extravasation while inadequate flow diminishes the penetration of resin into the accessory canals $[17,28]$.

The solubility of sealers is one of the requirements of using sealers in the root canal system. Solubility is directly related to the detachment of material components by interaction with fluids, creating gaps that might be populated by microorganisms leading to reinfection [24]. In this study, the solubility of epoxy resin-based sealer and sealer mixed with chitosan nanoparticles was $0.0051 \pm 0.0016 \%$ and $0.0045 \pm$ $0.0018 \%$, respectively. Thus, the results fulfilled the criteria of the requirements of ISO 6876, which stated that the loss of mass must not surpass $3 \%$ of the total weight. The solubility of both sealers was also low, and these results were in accordance with other previous studies $[5,18]$. The polymerization of the epoxy resin-based sealer is achieved through the reaction between hexamethylene tetraamine and bisphenol resin monomer to form a covalent bond; hence the polymer is heavily cross-linked, rigid, and durable resulting in low solubility [29]. This phenomenon may explain the low solubility of epoxy resin-based sealer and, as shown in SEM observation, seem homogenous and rough on the external surface.

This study also showed that the addition of chitosan in nanoparticle size, which acts as a filler in the epoxy resin-based sealer, leads to induce less solubility than an epoxy resin-based sealer. However, no significant difference occurred between both sealers $\left({ }^{*} \mathrm{P}>0.05\right)$, and both sealers had low solubility, according to ISO 6876. The solubility is of primary importance for a root canal sealer because successful results of endodontic treatment rely the majority on the sealer constituent integrity $[18,30]$. Degradation of the sealer may create voids and gaps in the interface of the sealer/dentin or the sealer/gutta-percha, leading to provide a pathway for microorganisms and their toxic products into periapical tissues [31]. Thus, the insolubility of root canal sealers might indeed influence the success of root canal treatment. Observation using SEM exhibited that both sealers surface presented micromorphological changes following the solubility test, and the epoxy resin-based sealer showed more obvious in micromorphological alteration.

\section{CONCLUSION}

The incorporation of chitosan nanoparticles produced a similar effect in setting time, flowability, and solubility as the epoxy resinbased sealer. Thus, epoxy resin-based sealer mixed with chitosan nanoparticles can be potential as a sealer in the future since it had acceptable properties in setting time, flowability, and solubility based on ISO 6876 standards.

\section{FUNDING}

This study was funded by Universitas Gadjah Mada, Faculty of Dentistry Grant (No. 4308/UN1/FKG1/Set. KG1/PT/2019).

\section{AUTHORS CONTRIBUTIONS}

All the authors have contributed equally.

\section{CONFLICT OF INTERESTS}

Authors declare no conflict of interest.

\section{REFERENCES}

1. Ashraf H, Najafi F, Heidari S, Mohammadian M, Zadsirjan S. Physical properties and chemical characterization of two experimental epoxy resin root canal sealers. Iran Endod J 2017;12:149-56.

2. Kaur A, Shah N, Logani A, Mishra N. Biotoxicity of commonly used root canal sealers: a meta-analysis. J Conservative Dent 2015;18:83-8.

3. Javidi M, Dastmalchi P, Zarei M, Rad MS, Ghorbani A. In vitro cytotoxicity of a new nano root canal sealer on human gingival fibroblasts. IEJ 2017;12:220-5.

4. Chang SW, Lee YK, Zhu Q, Shon WJ, Lee WC, Kum KY, et al. Comparison of the rheological properties of four root canal sealers. Int J Oral Sci 2015;7:56-61.

5. Poggio C, Dagna A, Ceci M, Meravini MV, Colombo M, Pietrocola G. Solubility and $\mathrm{pH}$ of bioceramic root canal sealers: a comparative study. J Clin Exp Dent 2017;9:e1189-e1194.

6. Colombo M, Poggio C, Dagna A, Meravini MV, Riva P, Trovati F, et al. Biological and physico-chemical properties of new root canal sealers. J Clin Exp Dent 2018;10:e120-e126.

7. Pawar SS, Pujar MA, Makandar SD. Evaluation of the apical sealing ability of bioceramic sealer, AH plus and epiphany: an in vitro study. J Conservative Dent 2014;17:579-82.

8. Nair N, Devadathan A, Johny MK, Mathew J, Jacob J. Comparative evaluation of antibiofilm efficacy of chitosan nanoparticle and zincoxide nanoparticle-incorporated calcium hydroxide-based Sealer: an in vitro study. Contemp Clin Dent 2018;9:434-9.

9. Desouky AA, Negm MM, Ali MM. Sealability of different root canal nanosealers: Nano calcium hydroxide and nano bioactive glass. Open Dent J 2019;13:308-15.

10. Brezhnev A, Neelakantan P, Tanaka R, Brezhnev S, Fokas G, Matinlinna JP. Antibacterial additives in epoxy resin-based root canal sealers: a focused review. Dent J 2019;7:1-27.

11. Reyhani MF, Ghasemi N, Rahimi S, Milani AS, Omrani E. Effect of different endodontic sealers on the push-out bond strength of fiber posts. Iran Endod J 2016;11:119-23.

12. Kodirkhonov M. Obtaining and characterization of the chitosan/carboxymetel cellulose interpolymer membrane by synthetic boundary method in analytical ultracentrifuge. JCR 2020;7:2749-57.

13. Simanjuntak PA, Djauharie N, Nursasongko B. Antibacterial effectiveness of $2 \%$ chitosan and $2 \%$ chlorhexidine againts Enterococcus Faecalis in biofilm (Laboratory experiment). Int J Appl Pharm 2019;11:44-8.

14. Charanteja RY, Jrganath S, Muni KU. Formulation and evaluation of chitosan nanoparticlesfor improved efficacy of itraconazole antifungal drug. Asian J Pharm Clin Res 2018;11:147-52.

15. International Organization for Standadization. Spesification for dental root canal sealing materials. ISO 6876. Geneva, Switzerland; 2001. 
16. Lee JK, Kwak SW, Ha JH, Lee WC, Kim HC. Physicochemical properties of epoxy resin-based and bioceramic-based root canal sealers. Bioinorg Chem Appl 2017;2017:1-9.

17. Zhou HM, Shen Y, Zheng W, Li L, Zheng YF, Haapasalo M. Physical properties of 5 root canal sealers. J Endod 2013;39:1281-6.

18. Altan H, Goztas Z, Inci G, Tosun G. Comparative evaluation of apical sealing ability of different root canal sealers. Eur Oral Res 2019;52:117-21.

19. Al-Nemrawi NK, Alsharif SSM, Dave RH. Preparation of chitosan-TPP nanoparticles: the influence of chitos, polymeric properties and formulation variables. Int J Appl Pharm 2018;10:60-5

20. Mendes AT, da Silva PB, So BB, Hashizume LN, Vivan RR, da Rosa RA, et al. Evaluation of physicochemical properties of new calcium silicate-based sealer. Braz Dent J 2018;29:536-40.

21. Flores DSH, Rached Junior FJA, Versiani MA, Guedes DFC, Sousa Neto MD, Pecora JD. Evaluation of physicochemical properties of four root canal sealers. Int Endod J 2011;44:126-35.

22. Viapiana R, Tanomaru JMG, Duarte MAH, Filho MT, Camilleri J. Chemical characterization and bioactivity of epoxy resin and portland cement-based sealers with niobium and zirconium oxide radiopacifiers. Dent Mater 2014;30:1005-20.

23. Teixeira VAB, De Carvalho H, Silva C, Alves OL, Luiz O, Reis A. Endodontic sealers modified with silver vanadate: antibacterial, compositional, and setting time valuation. Biomed Res Int 2019:19. https://doi.org/10.1155/2019/4676354.
24. Bronzel ZCL, Torres EFF, Filho TM, Andrade CGM, Martelo BR, Tanomaru GJM. Evaluation of physicochemical properties of a new calcium silicate-based sealer, bio-C sealer. J Endod 2019;45:1248-52.

25. Song YS, Choi Y, Lim MJ, Yu MK, Hong CU, Lee KW, et al. In vitro evaluation of a newly produced resin-based endodontic sealer. Restor Dent Endod 2016;41:189-95.

26. Lee JK, Kwak SW, Ha JH, Lee WC, Kim HC. Physicochemical properties of epoxy resin-based and bioceramic-based root canal sealers. Bioinorg Chem Appl 2017:1-21. https://doi.org/10.1155/2017/2582849.

27. Bernardes RA, de Amorim CA, Junior DSS, Pereira LO, Duarte MAH, Moraes IG, et al. Evaluation of the flow rate of 3 endodontic sealers: sealer 26, AH plus, and MTA obtura. Oral Surgery Oral Med Oral Pathol Oral Radiol Endod 2010;109:e47-e49.

28. Saad AY. Physicochemical, cytotoxicity, and biological properties of calcium silicate-based root canal sealers: a literature review. Saudi Endod J 2020;10:173-80.

29. Poggio C, Arciola CR, Dagna A, Colombo M, Bianchi S, Visai L. Solubility of root canal sealers: a comparative study. Int J Artif Organs 2010;33:676-81.

30. Ferrari F, Torres E, Tanomaru GJM, Martelo BR, Espir CG, Camilleri J. Solubility, porosity, dimensional and volumetric change of endodontic sealers. Braz Dent J 2019;30:368-73.

31. Canadas PS, Berástegui E, Gaton Hernandez P, Silva LA, Leite GA, Silva RS. Physicochemical properties and interfacial adaptation of root canal sealers. Braz Dent J 2014;25:435-41. 